\title{
Fasting in Ramadan Affects Cognitive and Physiological Function in Normal Subjects (Pilot Study)
}

\author{
Abdulrahman M. Alsharidah'1, Ghulam Murtaza², Muhannad M. Alsharidah¹, Shahid Bashir ${ }^{1 *}$ \\ ${ }^{1}$ Department of Physiology, Faculty of Medicine, King Saud University, Riyadh, Saudi Arabia \\ ${ }^{2}$ Department of Neurology, Faculty of Medicine, King Saud University, Riyadh, Saudi Arabia \\ Email: "sbashir10@gmail.com
}

Received 7 March 2016; accepted 30 May 2016; published 2 June 2016

Copyright (C) 2016 by authors and Scientific Research Publishing Inc.

This work is licensed under the Creative Commons Attribution International License (CC BY). http://creativecommons.org/licenses/by/4.0/

c) (i) Open Access

\begin{abstract}
Purpose: Our study aimed to investigate the effects of Ramadan fasting on cognitive and physiological function in a group of healthy Muslim subjects. Methods: We measured demographic, physiological (blood pressure), and cognitive function including attention switching task (AST) and delayed matching to sample (DMS) using the Cambridge Neuropsychological Test Automated Battery (CANTAB) at two periods of the study (before Ramadan, at the second week in Ramadan) in 15 subjects. Results: During fasting, performance on the AST test improved significantly for switching cost $(p=0.030)$ and for congruent condition of AST task $(p=0.043)$, for diastolic pressure decreased $(p=0.069)$ in healthy subjects. There was no significant effect for incongruent condition and number of errors and percent to complete task for DMS test and systolic blood pressure. Conclusions: The results suggest that Ramadan fasting is associated with significant changes in cognition, and causes a drop in diastolic blood pressure in healthy subject.
\end{abstract}

\section{Keywords}

Ramadan Fasting, Blood Pressure, Cognition

\section{Introduction}

Ramadan, the ninth month of the Islamic lunar calendar, is spent by adult Muslims fasting from all over the world. Fasting period commences just before dawn and lasts till sunset/dark [1]-[3]. During fasting Muslims remain away from drinking, eating, smoking, and sexual relations [4]. The duration of each period of fasting va-

\footnotetext{
${ }^{*}$ Corresponding author.
}

How to cite this paper: Alsharidah, A.M., Murtaza, G., Alsharidah, M.M. and Bashir, S. (2016) Fasting in Ramadan Affects Cognitive and Physiological Function in Normal Subjects (Pilot Study). Neuroscience \& Medicine, 7, 60-65. 
ries depending upon the solar calendar dates and geographical locations it occurs in. In summer months, it may last more than 16 hours a day.

A lot of research has been conducted to assess changes in different biological processes during Ramadan and their association with fasting [5]. Fasting in Ramadan may significantly affect daytime hydration, blood glucose and body temperature [6]-[8], circadian rhythms [9] [10], physiological [11], metabolic and endocrine functions [6] [8], serum levels of cholesterol, lipids [6]-[9]. In previous studies, effects of Ramadan on blood pressure were elaborated but such investigations were carried out in patients already suffering from hypertension and heart diseases [11] [12]. Limited data are available about effect of Ramadan fasting on normal individuals [13] [14].

Ramadan has marked impact on physical and cognitive performances [15]. Subjective alertness and memory functions are adversely affected [16]-[19]. On the other hand, relative robustness of memory, executive function, attention, information processing and verbal function during fasting has also been demonstrated in previous studies [20]-[23]. The conflicting findings may be attributed to methodological differences and the unavailability of sensitive computerized neuropsychological instruments in some studies.

Hence, our study was designed to examine the effect of Ramadan fasting in a group of healthy adult Muslim subjects on cognitive function and on blood pressure.

\section{Material and Methods}

\subsection{Subjects}

Fifteen healthy volunteers aged between 21 and 28 years $(24.5 \pm 2.7)$ were recruited from Riyadh, Saudi Arabia. Written informed consent was obtained and the study conducted in 2015. Questionnaires were given to all participants for knowing demographic data, diagnosed with diabetes, cognitive impairment, and visual analogue scale (Table 1). They were all enrolled in the study after receiving adequate verbal explanations about the research procedures and providing the informed consents.

\subsection{Procedure}

The study was conducted during the Ramadan fasting month. Participants were examined at two different points: two weeks before Ramadan, the 2nd week of fasting of Ramadan. Blood pressure and heart rate were measured during and after Ramadan.

\subsection{Cognitive Function}

Neuropsychological testing was performed using Cambridge Neuropsychological Test Automated Battery (CANTAB) research suite software (version 6. 0.37, Cambridge cognition). The entire battery required 25 - 30 min to complete the tests. Fist task was Delayed Matching to Sample (DMS), which assessed forced choice recognition memory for non-verbalis able patterns, testing both simultaneous matching and short-term visual memory. The participant was shown a complex visual pattern and then, after a brief delay, four similar patterns. The participant must touch the pattern, which exactly matches the sample. Second task was chosen from attention test, attention-switching task (AST). The test displayed an arrow, which can appear on either side of the screen (right or left) and can point in either direction (to the right or to the left). Each trial displayed a cue at the top of the screen that indicated to the participant whether they had to press the right or left button according to the "side on which the arrow appeared" or the "direction in which the arrow was pointing".

Table 1. Demographic data.
\begin{tabular}{cccc}
\hline Variable Study group & & & \\
\hline Age (Mean) $=$ & & 24.8 & Fon fasting $(\mathrm{N}=15)$ \\
Blood pressure & & & 24.8 \\
Systolic & $(\mathrm{mmHg})$ & 110.06 & 116.31 \\
Diastolic & & 74.6 & 73.42 \\
Heart rate & BPM & 71.86 & 69.47 \\
\hline
\end{tabular}

BPM: Beats per minute, mmHg: Millimeters of mercury. 


\subsection{Statistical Analysis}

DMS task was analyzed for the numbers of correct patterns selected, and statistical analysis measuring the probability of an error after a correct or incorrect response. AST test outcome measured include response latencies and error scores that reflected the participant's attention switching ability and the interference of congruent and incongruent task-irrelevant information. Statistical analysis was performed using SPSS software (version 19.0; SPSS Inc., Chicago, Illinois, USA). Comparison of quantitative data between Ramadan (fasting) and nonRamadan (non-fasting) was performed using paired t-tests if normality assumptions were satisfied; otherwise non-parametric tests were used. Two-tailed statistics were used and statistical significance set at $\mathrm{p}<0.05$.

\section{Results}

Results from Fifteen adult healthy volunteers were analyzed in this investigation (Table 1).

During fasting, performance on the AST test improved $(p=0.030)$ significantly for switching cost from (202 $\pm 49.2 \mathrm{~ms} \mathrm{SEM})$ to $(121 \pm 25.4$, Figure 1$)$ and improved latency $(\mathrm{ms})$ for congruent condition $(\mathrm{p}=0.043)$ from $(491 \pm 44.1)$ to $(412 \pm 32.1)$ of AST task (Figure 2) before and during Ramadan. There was non-significant ( $\mathrm{p}=$ $0.86)$ from $(508 \pm 45.6)$ to $(434 \pm 32.8)$ for response time after Ramadan.

There was near to significant $(p=0.006)$ decreased for diastolic pressure from $(77.4 \pm 1.69)$ to $(71.1 \pm 2.09)$ in healthy subjects (Table 1). There was not significant effect for incongruent condition $(p=0.149)$ and no of errors $(p=0.364)$ and percent to complete task for DMS test $(p=0.755)$ and systolic blood pressure $(p=0.882)$.

\section{Discussion}

Our data from neuropsychological test proposed that Ramadan fasting affects cognitive function but not homogenously. Ramadan had positive influence on performance in the domains of psychomotor function/processing speed and attention. Our data exhibited a marked decrease in values of diastolic blood pressure during Ramadan as compared to values obtained from healthy individuals before Ramadan. Since glucose is an essential substrate of central nervous system, cognitive activity is related to glucose metabolism [24] [25].

However, slower response times and performance decrements were observed [26]. Pivik et al. [27] investi-

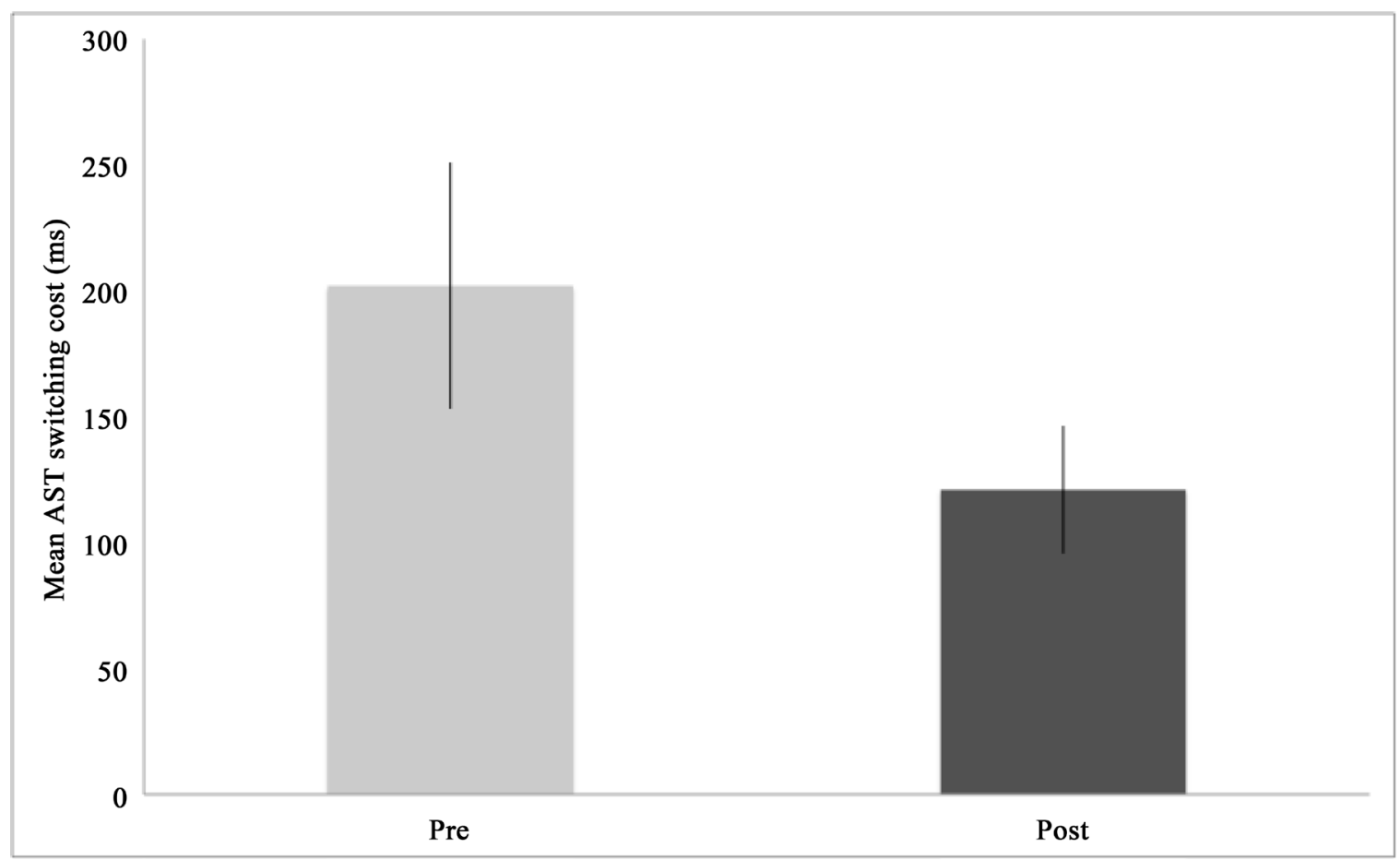

Figure 1. AST during non-fasting (pre) and fasting (post), for mean response time in (ms). Lower scores indicate better performance. 


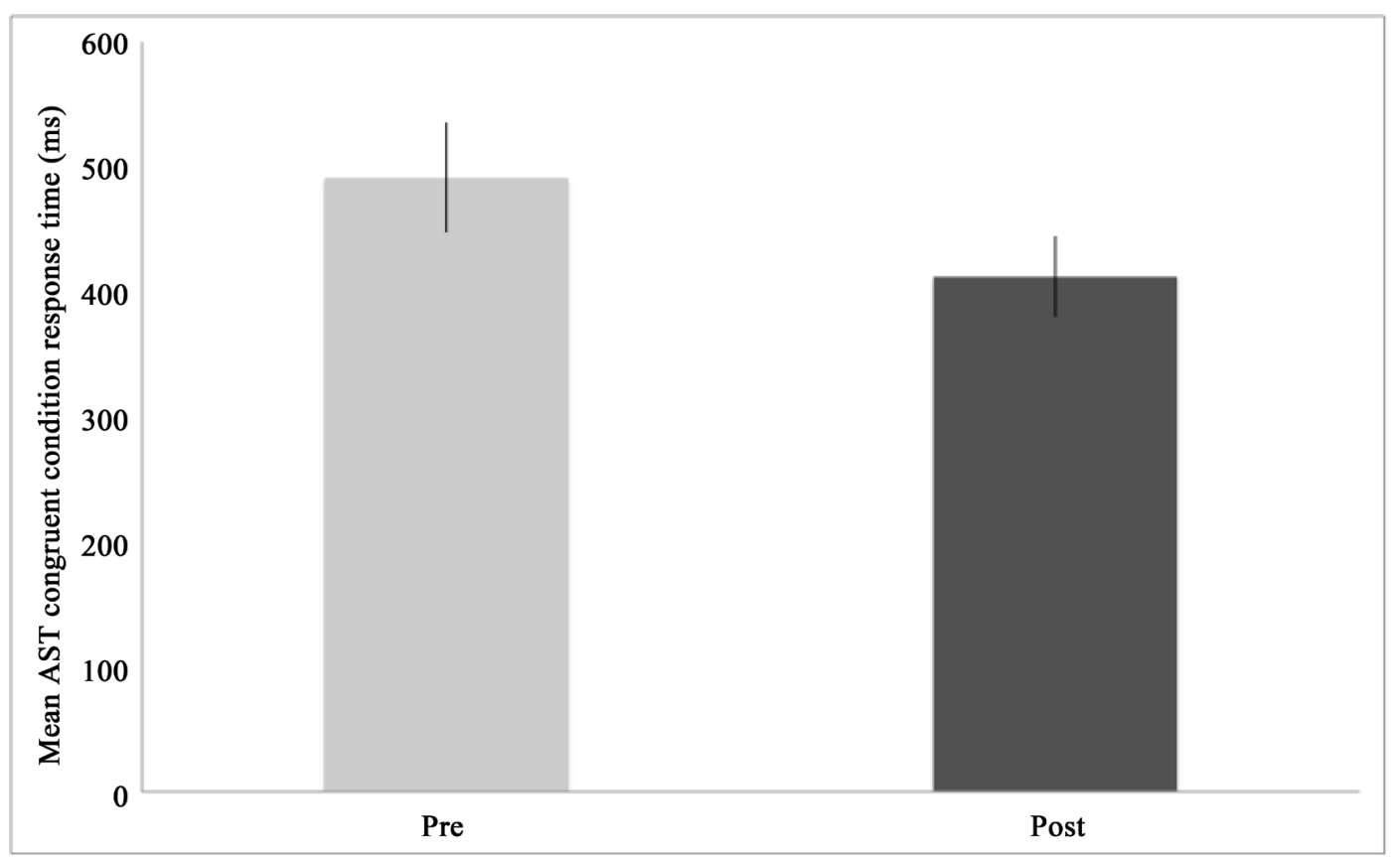

Figure 2. AST during non-fasting (pre) and fasting (post), for congruent condition mean response time in (ms). Lower scores indicate better performance.

gated effect of Ramadan fasting on occipital cortex and found that alpha frequency was not significantly altered in that specific area during fasting period. Similarly, in another Ramadan study, performance in occipital cortex domain was not declined in occipital cortex centered one-card learning and one-back memory tasks [15]-[17] [22].

Our data from Ramadan study are consistent with previously reported results. In our investigation, a significant drop of diastolic blood pressure (to $7.33 \mathrm{mmHg}$ ) was recorded during fasting. Dewanti et al. [28] observed comparable hypotensive effects on both fasting and non-fasting groups. In this way, these results cast suspicion on those studies in which effect of Ramadan fasting was investigated in patients diagnosed with hypertension. We recommend to record data with caution from those individuals who are habitual fasters and diagnosed with heart diseases. Large sample size containing female fasters and individuals from other ethnicities would be needed for further investigations.

\section{Conclusion}

Our results confirm that during Ramadan fasting, performance in cognitive functions requiring sustained rapid responses is better, whereas performance in non-speed dependent accuracy measures is more resilient.

\section{Acknowledgements}

Work on this study was supported by grants from Deanship of Scientific Research grant (RGP-216) King Saud University, Saudi Arabia.

\section{References}

[1] Samad, F., Qazi, F., Pervaiz, M.B., Kella, D.K., Mansoor, M., Osmani, B.Z., et al. (2015) Effect of Ramadan Fasting on Blood Pressure in Normotensive Males. Journal of Ayub Medical College Abbottabad, 27, 338-342.

[2] Farooq, A., Herrera, C.P., Almudahka, F. and Mansour, R. (2015) A Prospective Study of the Physiological and Neurobehavioral Effects of Ramadan Fasting in Preteen and Teenage Boys. Journal of the Academy of Nutrition and Dietetics, 115, 889-897. http://dx.doi.org/10.1016/j.jand.2015.02.012

[3] Meo, S.A. and Hassan, A. (2015) Physiological Changes during Fasting in Ramadan. Journal of the Pakistan Medical Association, 65, S6-S14. 
[4] Roky, R., Chapotot, F., Benchekroun, M.T., Benaji, B., Hakkou, F., Elkhalifi, H., et al. (2003) Daytime Sleepiness during Ramadan Intermittent Fasting: Polysomnographic and Quantitative Waking EEG Study. Journal of Sleep Research, 12, 95-101. http://dx.doi.org/10.1046/j.1365-2869.2003.00341.x

[5] Roky, R., Houti, I., Moussamih, S., et al. (2004) Physiological and Chronobiological Changes during Ramadan Intermittent Fasting. Annals of Nutrition and Metabolism, 48, 296-303. http://dx.doi.org/10.1159/000081076

[6] Leiper, J.B., Molla, A.M. and Molla, A.M. (2003) Effects on Health of Fluid Restriction during Fasting in Ramadan. European Journal of Clinical Nutrition, 57, S30-S38. http://dx.doi.org/10.1038/sj.ejcn.1601899

[7] Nomani, M.Z., Hallak, M.H., Nomani, S., et al. (1989) Changes in Blood Urea and Glucose and Their Association with Energy Containing Nutrients in Men on Hypocaloric Diets during Ramadan Fasting. The American Journal of Clinical Nutrition, 49, 1141-1145.

[8] Larijani, B., Zahedi, F., Sanjari, M., et al. (2003) The Effect of Ramadan Fasting on Fasting Serum Glucose in Healthy Adults. Medical Journal of Malaysia, 58, 678-680.

[9] Temizhan, A., Donderici, O., Ouz, D. and Demirbas, B. (1999) Is There Any Effect of Ramadan Fasting on Acute Coronary Heart Disease Events? International Journal of Cardiology, 70, 149-153. http://dx.doi.org/10.1016/S0167-5273(99)00082-0

[10] Perk, G., Ghanem, J., Aamar, S., Ben-Ishay, D. and Bursztyn, M. (2001) The Effect of the Fast of Ramadan on Ambulatory Blood Pressure in Treated Hypertensives. Journal of Human Hypertension, 15, 723-725. http://dx.doi.org/10.1038/sj.jhh.1001262

[11] Habbal, R., Azzouzi, L., Adnan, K., Tahiri, A. and Chraibi, N. (1998) Variations of Blood Pressure during the Month of Ramadan. Archives des Maladies du Coeur et des Vaisseaux, 91, 995-998.

[12] Monk, T.H., Folkard, S. and Leng, V.C. (1983) Circadian Rhythms in Subjective Alertness and Core Body Temperature. Chronobiologia, 10, 49-55.

[13] Aziz, A.R. and Png, W. (2008) Practical Tips to Exercise Training during the Ramadan Fasting Month. Institut Sukan Negara Bulletin, 1, 13-19.

[14] Hakkou, F., Wast, D. and Jaouen, C. (1988) Does Ramadan Impair Vigilance and Memory. Psychopharmacology, 96, 213.

[15] Ali, M.R. and Amir, T. (1989) Effects of Fasting on Visual Flicker Fusion. Perceptual \& Motor Skills, 69, 627-631. http://dx.doi.org/10.2466/pms.1989.69.2.627

[16] Hakkou, F., Iraki, L. and Tazi, A. (1994) Ramadan, Chronobiology and Health. ChronobiolInt, 11, 340-342. http://dx.doi.org/10.3109/07420529409057250

[17] Green, M.W., Elliman, N.A. and Rogers, P.J. (1995) Lack of Effect of Short-Term Fasting on Cognitive Function. Journal of Psychiatric Research, 29, 245-253. http://dx.doi.org/10.1016/0022-3956(95)00009-T

[18] Donohoe, R.T. and Benton, D. (1999) Cognitive Functioning Is Susceptible to the Level of Blood Glucose. Psychopharmacology (Berlin), 145, 378-385. http://dx.doi.org/10.1007/s002130051071

[19] Hertz, L. and Dienel, G.A. (2002) Energy Metabolism in the Brain. International Review of Neurobiology, 51, 1-102. http://dx.doi.org/10.1016/S0074-7742(02)51003-5

[20] Liebermeister, H. and Schroter, K. (1983) Absence of Detrimental Changes of Cognitive Parameters during Fasting. International Journal of Obesity, 7, 45-51.

[21] Gutierrez, A., Gonzalez-Gross, M., Delgado, M., et al. (2001) Three Days Fast in Sportsmen Decreases Physical Work Capacity But Not Strength or Perception-Reaction Time. International Journal of Sport Nutrition and Exercise Metabolism, 11, 420-429.

[22] Szinnai, G., Schachinger, H., Arnaud, M.J., et al. (2005) Effect of Water Deprivation on Cognitive-Motor Performance in Healthy Men and Women. American Journal of Physiology. Regulatory, Integrative and Comparative Physiology, 289, 275-280. http://dx.doi.org/10.1152/ajpregu.00501.2004

[23] Pivik, R.T. and Dykman, R.A. (2007) Event-Related Variations in Alpha Band Activity during an Attentional Task in Preadolescents: Effect of Morning Nutrition. Clinical Neurophysiology, 118, 615-632. http://dx.doi.org/10.1016/j.clinph.2006.11.003

[24] Liebermeister, H. and Schroter, K. (1983) Absence of Detrimental Changes of Cognitive Parameters during Fasting. International Journal of Obesity, 7, 45-51.

[25] Green, M.W., Elliman, N.A. and Rogers, P.J. (1995) Lack of Effect of Short-Term Fasting on Cognitive Function. Journal of Psychiatric Research, 29, 245-253. http://dx.doi.org/10.1016/0022-3956(95)00009-T

[26] Green, M.W., Elliman, N. and Rogers, P.J. (1997) The Effects of Food Deprivation and Incentive Motivation on Blood Glucose Levels and Cognitive Function. Psychopharmacology (Berlin), 134, 88-94. http://dx.doi.org/10.1007/s002130050429 
[27] Doniger, G.M., Simon, E.S. and Zivotofsky, A.Z. (2006) Comprehensive Computerized Assessment of Cognitive Sequelae of a Complete 12-16 Hour Fast. Behavioral Neuroscience, 120, 804-816. http://dx.doi.org/10.1037/0735-7044.120.4.804

[28] Dewanti, L., Watanabe, C., Sulistiawati, E. and Ohtsuka, R. (2006) Unexpected Changes in Blood Pressure and Hematological Parameters among Fasting and Nonfasting Workers during Ramadan in Indonesia. European Journal of Clinical Nutrition, 60, 877-881. http://dx.doi.org/10.1038/sj.ejcn.1602393 